\title{
Experimental Study of the Effectiveness of Sacrificial Cladding Using Polymeric Foams as Crushable Core with a Simply Supported Steel Beam
}

\author{
H. Ousji, ${ }^{1,2}$ B. Belkassem, ${ }^{1}$ M. A. Louar, ${ }^{1,2}$ B. Reymen, ${ }^{1}$ L. Pyl, ${ }^{2}$ and J. Vantomme ${ }^{1}$ \\ ${ }^{1}$ Civil and Materials Engineering Department, Royal Military Academy (RMA), Av. de la Renaissance 30, 1000 Brussels, Belgium \\ ${ }^{2}$ Department of Mechanics of Materials and Constructions, Vrije Universiteit Brussel (VUB), Pleinlaan 2, 1050 Brussels, Belgium \\ Correspondence should be addressed to H. Ousji; hamza.ousji@rma.ac.be
}

Received 21 April 2016; Accepted 4 August 2016

Academic Editor: Li Chen

Copyright (@) 2016 H. Ousji et al. This is an open access article distributed under the Creative Commons Attribution License, which permits unrestricted use, distribution, and reproduction in any medium, provided the original work is properly cited.

\begin{abstract}
The present paper focuses on the study of the effectiveness of the sacrificial cladding using polymeric foam as crushable core to reduce the delivered blast energy using a simplified structure. The latter consists of a simply supported steel beam under a localized blast load. The tested sacrificial cladding has a cross-sectional area of $80 \times 80 \mathrm{~mm}^{2}$. The effect of the front plate mass and the crushable core properties (plateau stress and thickness) is studied. Three polymeric foams are investigated: (a) the expanded polystyrene foam (PS13) with a density of $13 \mathrm{~kg} / \mathrm{m}^{3}$, (b) the closed-cell polyurethane (PU30) with a density of $30 \mathrm{~kg} / \mathrm{m}^{3}$, and (c) the open-cell polyurethane (PU50) with a density of $50 \mathrm{~kg} / \mathrm{m}^{3}$. Four front plate masses are used: 144, 188, 336, and $495 \mathrm{~g}$. All possible combinations are tested to determine their absorption capacity. The obtained results show that the absorption capability increases by increasing the front plate mass, the plateau stress, and the thickness of the crushable core. The open-cell polyurethane PU50 performs better. Disintegration problems are observed on the expanded polystyrene PS13 after the end of the compression process.
\end{abstract}

\section{Introduction}

Significant effects are observed after accidental and intentional explosions. This makes protective techniques necessary to ensure survivability. Considerable research has been conducted on the study of protective structures aiming at reducing the transmitted pressure to the main structure. Sacrificial cladding structures receive a lot of attention [1-10]. They consist of a crushable core between the main structure and a front plate. The core material is often a cellular solid allowing large plastic deformation under relatively low constant stress (plateau stress, which is the average stress of the plastic region of the stress-strain curve of the crushable core) [1-8, 11-13]. In order to control the magnitude of the transmitted pressure to the main structure and to guarantee an optimal design of the sacrificial cladding, the study of the effectiveness and the determination of the absorption capacity of a given sacrificial cladding configuration is needed.

Both crushable materials and structures are used as sacrificial cladding core. Aluminium foams and honeycomb structures receive a lot of attention $[1-9,11,12]$; the absorption mechanism, the dynamic behaviour, the effect of the front plate (mass and rigidity), and the crushable core properties are analysed. However, these cores are characterized by a relatively high plateau stress (between 1 and $10 \mathrm{MPa}$ [14]) to protect a given structure. $\mathrm{Wu}$ and Zhou [9] study the use of foam cladding to protect a simply supported reinforced concrete (RC) slab against blast loading. They use an adapted SDOF model supported by a full scale experiment to study the effectiveness of aluminium foam on RC slab. They observe that the aluminium foam is not completely compacted and cracks are significant in depth and along the length of the slab. They explained the obtained results by the higher plateau stress transmitted to the main structure [3]. Xia et al. [8] perform a series of full scale experiments to study the effectiveness of graded density aluminium foam on RC slab under blast loading. The idea of the density-graded foam consists in the use of foam structure with various densities along its thickness in order to increase the overall energy absorbing capacity of aluminium foam while keeping 
the transmitted stress at a reasonable low magnitude. Several density combinations test to protect a simply supported RC slab. They observe that an ascending density from bottom to top can improve the blast resistance compared to a foam with a uniform density. Yet, cracks and damage appear even with protection layers. Hence, a crushable core with lower plateau stress such as polymeric foam is required. However, research on the effectiveness of polymeric foams as crushable core is rather limited.

In literature, the pendulum (mainly the four-cable pendulum) is mostly used to experimentally study the effectiveness of several sacrificial cladding configurations $[1,6,11,12]$. The pendulum system is used to measure the impulse by recording the horizontal displacement of the pendulum mass. However, the absorption capacity cannot be quantified from the available experimental results. For example, using a pendulum setup, Hanssen et al. [1] investigate the absorption capability of aluminium foam in order to reduce the delivered blast energy. They observed that the foam is unable to reduce the global response of the pendulum and thus the absorption capacity of the foam material cannot be calculated. Ma and Ye [3] explain that the results are understandable because the main structure design (the pendulum system) is not appropriate for blast mitigation measurements. To reach an effective protection, the resistance of the main structure and the resistance of the sacrificial cladding, in particular the crushable core, should be comparable [3]. The resistance of the crushable core is governed by the plateau stress. But the resistance of the pendulum system of Hanssen is 500 times lower than the resistance of the aluminium foam [3]. Hence, a design of an appropriate experimental setup, adapted to the investigated crushable material, is needed to evaluate the effectiveness of the sacrificial cladding.

The aim of the present paper is to study the effectiveness of sacrificial cladding using polymeric foam as crushable core by means of an adequate experimental setup. The design of the experimental setup is derived from the Ma and Ye theory [3]. The main structure is simulated by a simply supported steel beam under a localized blast load. The influence of the front plate mass and the crushable core properties (thickness and plateau stress) on the effectiveness is investigated. The studied sacrificial cladding is composed of combinations of the following parts:

(i) Three polymeric foams: (a) the expanded polystyrene foam with a density of $13 \mathrm{~kg} / \mathrm{m}^{3}$, (b) the closed-cell polyurethane with a density of $30 \mathrm{~kg} / \mathrm{m}^{3}$, and (c) the open-cell polyurethane with a density of $50 \mathrm{~kg} / \mathrm{m}^{3}$, labeled as PS13, PU30, and PU50, respectively.

(ii) Four metallic front plates with different masses (144, 188,336 , and $495 \mathrm{~g}$ ) labeled as FP1, FP2, FP3, and FP4, respectively.

The present paper is divided into four parts. First, a description of the material properties of both the main structure and the investigated crushable cores is presented. Second, a brief explanation of the Ma and Ye theory, used to select the adequate experimental setup, is presented. Third, a detailed description of the experimental setup and the
TABLE 1: Mechanical properties of S355JR steel.

\begin{tabular}{lccc}
\hline$\rho\left(\mathrm{kg} / \mathrm{m}^{3}\right)$ & $E(\mathrm{GPa})$ & $\mathrm{Re}_{0.2}(\mathrm{MPa})$ & $R_{m}(\mathrm{MPa})$ \\
\hline 7830 & 240 & 353.85 & 491.78 \\
\hline
\end{tabular}

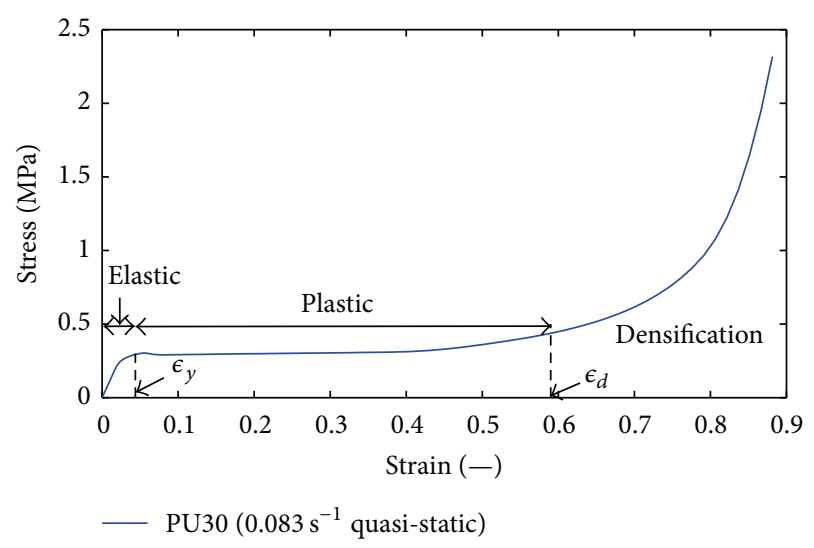

FIGURE 1: Stress-strain response of the closed-cell polyurethane PU30 under quasi-static compression load.

obtained results are presented. The effectiveness of the sacrificial cladding is illustrated. Finally, conclusions and perspectives are given.

\section{Test Materials}

Two material kinds are used: polymeric foams and steel. The polymeric foam is used as crushable core of the sacrificial cladding. The steel is used for the simply supported beam. These materials are selected on the basis of the Ma and Ye [3] theory (see Section 3).

2.1. Steel. S355JR steel is used for the main structure, which consists of a simply supported steel beam. The beam specimens $\left(700 \times 80 \times 5 \mathrm{~mm}^{3}\right)$ are cut from $6 \mathrm{~m}$ long flat steel bars with a span of $600 \mathrm{~mm}$. Based on tensile test results, the mechanical properties are summarized in Table 1 , where $\rho$ stands for the steel density, $E$ is Young's modulus, $\mathrm{Re}_{0.2}$ is the yield stress, and $R_{m}$ is the tensile strength.

2.2. Polymeric Foam. Three polymeric foams are used as crushable core: the expanded polystyrene foam with a density of $13 \mathrm{~kg} / \mathrm{m}^{3}$, the closed-cell polyurethane with a density of $30 \mathrm{~kg} / \mathrm{m}^{3}$, and the open-cell polyurethane with a density of $50 \mathrm{~kg} / \mathrm{m}^{3}$ (labeled as PS13, PU30, and PU50, resp.). These materials are used in compression to absorb the generated blast energy. The uniaxial compressive stress-strain response for quasi-static as well as dynamic loading is divided into three distinct regions: elastic, plastic, and densification region (Figure 1). Two main parameters should be taken into account: the plateau stress $\sigma_{c}$ which characterizes the relatively constant stress in the plastic region and the densification strain $\epsilon_{d}$ which marks the beginning of the densification behaviour. According to the development of Li et al. [16], the densification strain $\epsilon_{d}$ is the point where the energy 
TABLE 2: Mechanical properties of the considered polymeric foams.

\begin{tabular}{lcccc}
\hline \multicolumn{1}{c}{ Properties } & & PS13 [15] & PU30 & PU50 \\
\hline Density & $\left(\mathrm{kg} / \mathrm{m}^{3}\right)$ & 13 & 30 & 50 \\
Young's modulus & $(\mathrm{MPa})$ & 2.7 & 11.36 & 7.45 \\
Plateau stress & $(\mathrm{MPa})$ & 0.153 & 0.323 & 0.444 \\
Densification strain & $(-)$ & 0.7 & 0.59 & 0.63 \\
\hline
\end{tabular}

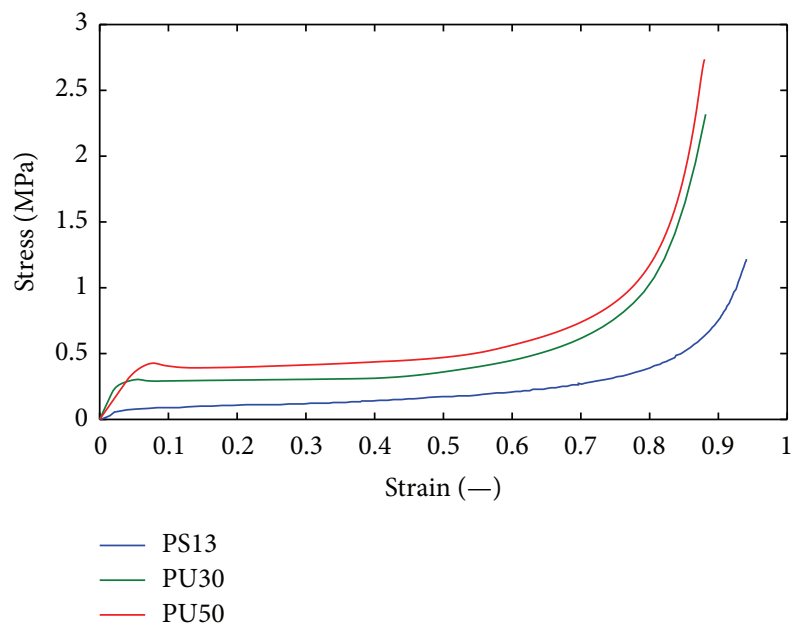

FIGURE 2: Stress-strain response of PS13 $\left(0.001 \mathrm{~s}^{-1}\right)$ [15], PU30, and PU50 $\left(0.083 \mathrm{~s}^{-1}\right)$ under quasi-static compression.

absorption efficiency, given in (1), reaches a maximum on the efficiency-strain curve. The plateau stress is calculated by means of (2) where $\epsilon_{y}$ stands for the strain corresponding to the start of the plastic behaviour.

$$
\begin{gathered}
\eta(\epsilon)=\frac{1}{\sigma(\epsilon)} \int_{\epsilon_{y}}^{\epsilon} \sigma(\epsilon) d \epsilon, \\
\sigma_{c}=\frac{\int_{\epsilon_{y}}^{\epsilon_{d}} \sigma(\epsilon) d \epsilon}{\epsilon_{d}-\epsilon_{y}} .
\end{gathered}
$$

The quasi-static responses of the tested foams are depicted in Figure 2. The mechanical properties are summarized in Table 2. The compression test of the expanded polystyrene foam is taken from Chen et al. [15].

\section{Sacrificial Cladding and Main Structure Selection}

According to the analytical Load-Cladding-Structure (LCS) model developed by Ma and Ye [3], the choice of the sacrificial cladding configuration should be adapted to the main structure properties. The main structure is simplified to a single degree of freedom system (SDOF); see Figure 3, where $k$ stands for the main structure stiffness, $m_{\text {se }}$ stands for the equivalent mass of the beam, $A$ stands for the cross-sectional area of the front plate, and $P(t)$ stands for the reflected pressure time history. The transmitted pressure to the main structure before the complete densification of the crushable core is governed by the plateau stress $\sigma_{c}$. The crushable core



FIGURE 3: Simplified interaction between the sacrificial cladding and the main structure given by $\mathrm{Ma}$ and $\mathrm{Ye}[3]$.

resistance, the product of the cross-sectional area of the front plate $A$, and plateau stress $\sigma_{c}$ should be comparable with the maximum resistance of the main structure $\left(k y_{c}\right)$. When the plateau stress is very low, $\sigma_{c} A \ll k y_{c}$, the foam deforms even at lower load than the structure resistance $\left(\sigma_{c} A<P_{0} A<\right.$ $\left.k y_{c}\right)$. When the plateau stress is very high, $\sigma_{c} A \gg k y_{c}$, the transmitted pressure to the main structure is higher than the allowable load (structure resistance) leading to a higher deflection of the structure $\left(>y_{c}\right)$.

According to the same theory, the front plate should be stopped before reaching the densification region of the crushable core and the critical deflection of the structure. A minimum thickness of the crushable material is needed which depends on the front plate mass $M_{1}$, the plateau stress $\sigma_{c}$, the total impulse $I$, and the maximum reflected pressure $P_{0}$.

As a conclusion, an optimal combination of the front plate mass, the crushable core properties (plateau stress and thickness), and the main structure is essential to ensure the desirable absorption capacity. In the present work, we have the following:

(i) The main structure is simulated by a simply supported steel beam under a localized load. The steel beam has a width of $80 \mathrm{~mm}$, a thickness of $5 \mathrm{~mm}$, and a span of $600 \mathrm{~mm}$. It is characterized by a maximum resistance $R_{\max }$ of $1.3 \mathrm{kN}$ obtained by applying the SDOF theory (see Section 4.2).

(ii) The studied sacrificial cladding is composed of combinations of the following parts:

(a) Three polymeric foams: (a) the expanded polystyrene foam with a density of $13 \mathrm{~kg} / \mathrm{m}^{3}$, (b) the closed-cell polyurethane with a density of $30 \mathrm{~kg} / \mathrm{m}^{3}$, and (c) the open-cell polyurethane with a density of $50 \mathrm{~kg} / \mathrm{m}^{3}$; the corresponding plateau stresses being compared with $R_{\max }$ : $A \sigma_{c}(\mathrm{PS} 13)=0.98 \mathrm{kN}<R_{\max }<A \sigma_{c}(\mathrm{PU} 30)=$ $2.07 \mathrm{kN}<\sigma_{c} A($ PU50) $=2.84 \mathrm{kN}$.

(b) A steel front plate with four different masses $(144,188,336$, and $495 \mathrm{~g})$.

\section{Experimental Study}

The goal of the experimental part is to study the effectiveness of sacrificial cladding using a polymeric foam as crushable 




(a)

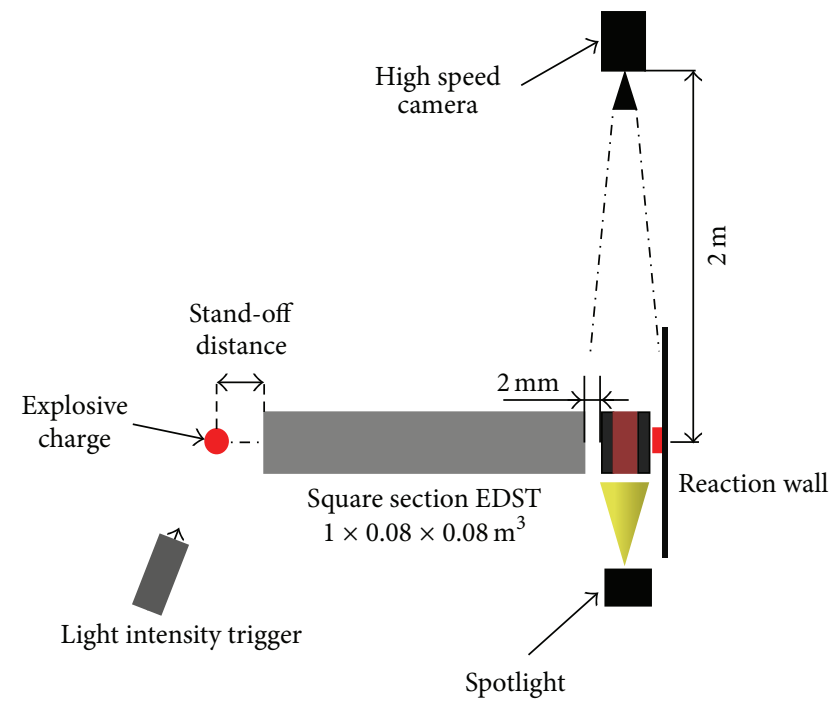

(c)

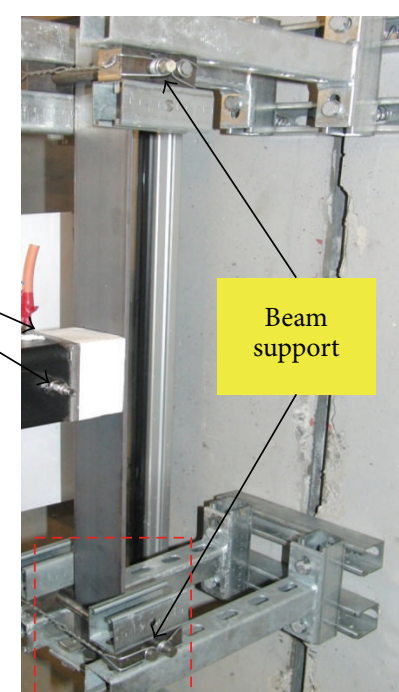

(b)

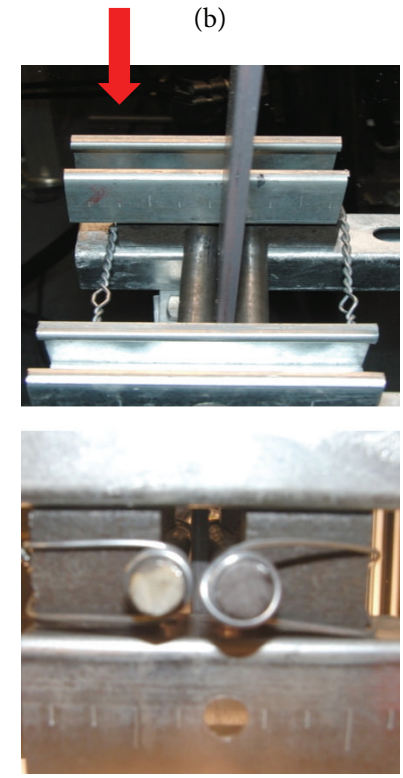

(d)

FIGURE 4: (a) Experimental setup, (b) beam support, (c) schematic representation of the experimental setup, and (d) simple support of the steel beam.

core with a simply supported steel beam. To fulfill this aim, three parts are developed:

(i) First, a description of the experimental setup is presented.

(ii) Second, the beam response without sacrificial cladding is discussed.

(iii) Third, the effectiveness of the sacrificial cladding is analysed by studying the effect of both the crushable core properties (plateau stress and thickness) and the front plate mass.

4.1. Experimental Setup. A series of experimental tests are performed using the experimental setup shown in Figure 4. A schematic representation is given in Figure 4(c). A square section explosive driven shock tube (EDST) is used to generate a planar blast wave at its end [17]. The used EDST is a steel square section tube with an inner edge of $70 \mathrm{~mm}$, a thickness of $5 \mathrm{~mm}$, and a length of $1 \mathrm{~m}$. At the entrance, the tube is reinforced over the first $150 \mathrm{~mm}$. The blast wave at the tube end is governed by the explosive mass $(W)$ and the stand-off distance (the distance between the explosive charge and the EDST entrance). In order to avoid the impact between the beam and the tube during the beam oscillation, the blast load is chosen such as to ensure sufficient plastic deformation. This load is obtained by detonating $10 \mathrm{~g}$ of $\mathrm{C} 4$ set at $5 \mathrm{~mm}$ from the tube entrance. The maximum reflected overpressure and impulse at $2 \mathrm{~mm}$ from the tube end are 13.85 $\mathrm{MPa}$ and $2250 \mathrm{~Pa} \cdot \mathrm{s}$ with a standard deviation of $7.75 \%$ and $4.31 \%$, respectively. The planarity is checked and reported in [18]. The reflected pressure profile is given in Figure 5. In 


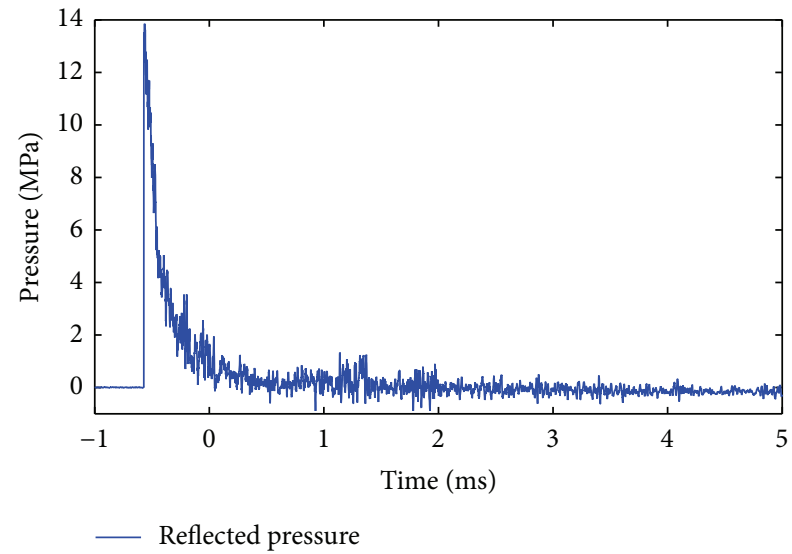

FIGURE 5: Reflected pressure measured at $2 \mathrm{~mm}$ after the EDST end generated by detonating $10 \mathrm{~g}$ of $\mathrm{C} 4$ set at a stand-off distance of $5 \mathrm{~mm}$ from the entrance of the EDST.

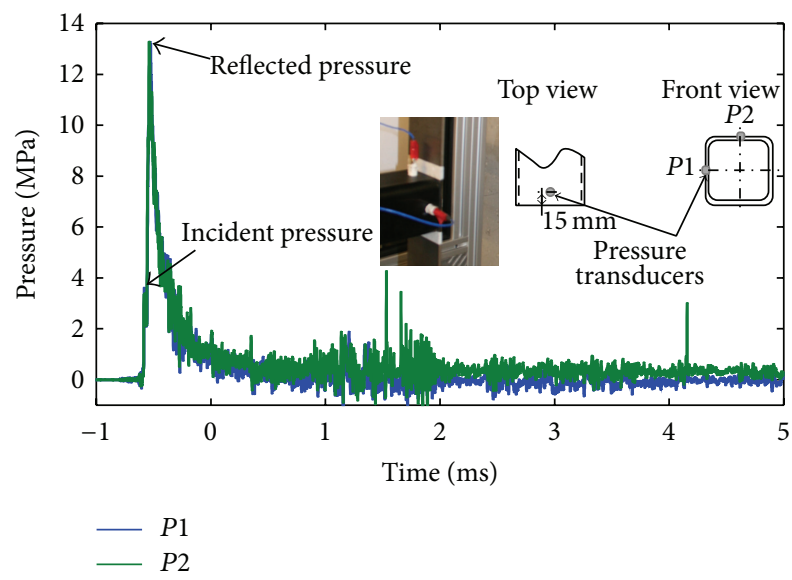

FIGURE 6: Pressure time signal measured at the tube end by pressure transducers $P 1$ and $P 2$ using $10 \mathrm{~g}$ of $\mathrm{C} 4$ set at a stand-off distance of $5 \mathrm{~mm}$ from the entrance of the EDST.

the present work, the pressure-impulse combination is kept identical for all experiments.

At the tube end (Figure 4(b)), two pressure transducers $(P 1$ and $P 2)$ are mounted to measure the pressure at two different faces of the tube end. These measurements are used to check the repeatability of the applied over the different experiments. Figure 6 presents typical $P 1$ and $P 2$ measurements where two peaks can be identified: the first one is the incident pressure and the second one is the reflected pressure measured at the locations of $P 1$ and $P 2$.

At $2 \mathrm{~mm}$ after the end of the EDST end, sacrificial cladding configuration is fixed to the middle of the steel beam. The sacrificial cladding has a dimension of $80 \times$ $80 \mathrm{~mm}^{2}$ (see Figure 4(c)) and is composed of a front plate and a crushable core. These three components (front plate, crushable material, and steel beam) are bonded together by means of double-sided bonding tape. The steel beam is simply supported and has a span of $0.6 \mathrm{~m}$, a width of $80 \mathrm{~mm}$, and a thickness of $5 \mathrm{~mm}$. The steel beam supports are ensured by two steel cylinders for both extremities as shown in
Figure 4(d). Two high speed cameras (HSCl and HSC2), Photron Fastcam SA5, are used to record the sacrificial cladding crushing and the beam deflection and to check the boundary conditions. Measurements are triggered by a light intensity trigger.

4.2. Beam Response without Sacrificial Cladding. The deflection of the simply supported beam under a localized blast load is discussed. Figure 7(a) illustrates the tracking of a point at midspan using a Labview code. The resulting deflections (three tests are performed for reproducibility) are plotted in Figure 7(c). A maximum deflection of $104 \mathrm{~mm}$ and a permanent plastic deflection of $57.57 \mathrm{~mm}$ with a relative standard deviation of $4.51 \%$ are recorded. The free vibration period $T_{0}$ is $32 \mathrm{~ms}$. The time ratio between the positive phase duration $\left(t_{d}=0.324 \mathrm{~ms}\right)$ and the free vibration period of the structure $t_{d} / T_{0}$ is about $10^{-2}$ which corresponds to an impulsive loading.

For simplicity purposes and in order to limit the needed amount of parameters (Figure 8), the idealized elastic-plastic model is adopted for the resistance function of the beam. Regarding the values of the elastic deflection $y_{e}$ and the stiffness $k$, the stiffness is computed and given in Table 3 , and the elastic deflection $y_{e}$ is obtained from the deflectiontime history results. Up to the first maximum deflection, two slopes are observed due to the change of the beam resistance from the elastic to the plastic behaviour (Figure $7(\mathrm{c}))$. The time at which this change occurs is identified from the derivation of the deflection-time history. Hence, the corresponding elastic deflection $y_{e}$ of $39 \mathrm{~mm}$ is found. The maximum structure resistance $R_{\max }\left(k y_{e}\right)$ equals $1.4 \mathrm{kN}$. The dissipated energy can be obtained from the surface under the response function curve.

The experimental results are compared with the single degree of freedom theory [19]. The case study is simplified to a simply supported beam under a punctual load (Figure 7(b)). The formula and the corresponding values are listed in Table 3. The experimental results are in concordance with the analytical prediction with a maximum relative difference of about $12 \%(k)$.

4.3. Beam Response with Sacrificial Cladding. 14 configurations are investigated; see Table 4 . Every configuration is repeated three times to check the repeatability of the measurements. A maximum relative standard deviation of the beam deflection of 7.10\% is recorded. Several sacrificial cladding configurations are tested to analyse the effect of both the crushable material (plateau stress and thickness) and the front plate mass. The experimental results are summarized in Table 4: the maximum deflection $y_{\max }$, the permanent plastic deformation $y_{\text {plastic }}$, the free vibration period $T_{0}$, the maximum strain in the crushable core $\epsilon_{\max }$, the initial front plate velocity $v_{0}$, and the absorption capacity Eff of the sacrificial cladding configuration. The absorption capacity Eff is calculated by comparing $E_{0}$, the dissipated energy in the steel beam without sacrificial cladding, with $E_{\mathrm{sc}}$ the dissipated energy in the steel beam with sacrificial cladding.

$$
\mathrm{Eff}=\frac{E_{0}-E_{\mathrm{sc}}}{E_{0}} 100 \%=\frac{y_{\max }-y_{\max }(\mathrm{sc})}{y_{\max }-y_{e} / 2} 100 \%,
$$




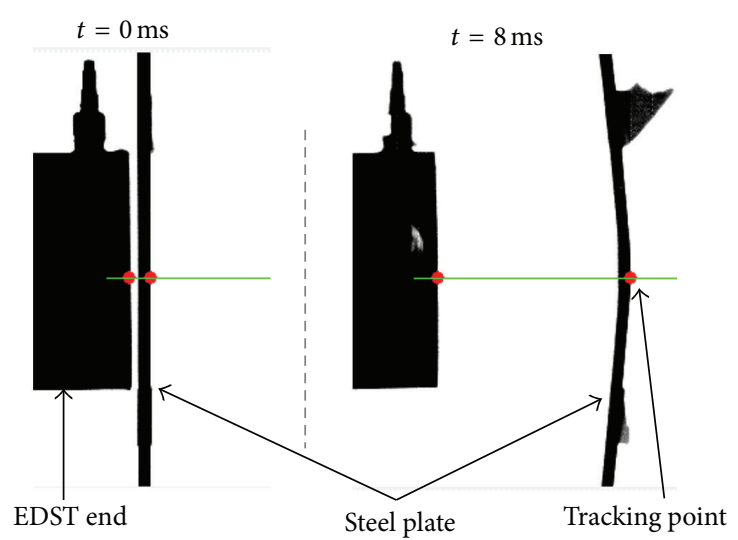

(a)



(b)

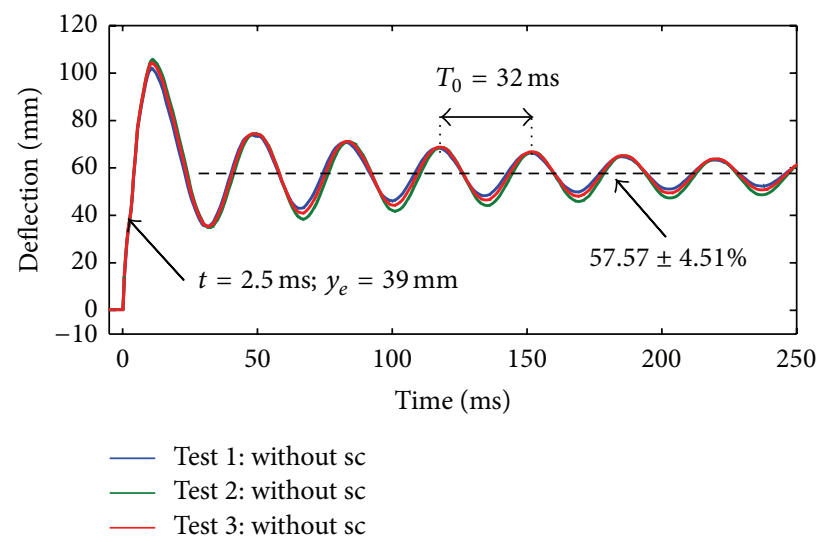

(c)

FIGURE 7: (a) Labview code used to track the middle point of the simply supported beam based on the video recorded by HSC1, (b) the equivalent SDOF system, and (c) the midspan response of a simply supported beam under a localized blast load for three tests.

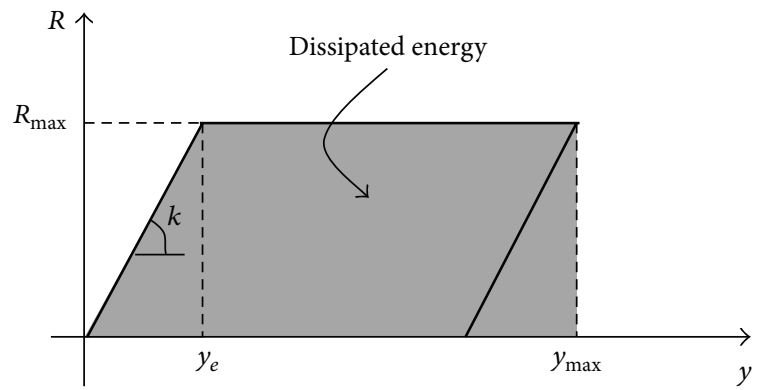

Figure 8: The idealized elastic-plastic response function [19].

where $y_{\max }(\mathrm{sc})$ stands for the maximum deflection of the steel beam with sacrificial cladding. In order to facilitate the comparison, configurations are labeled as $X 1-X 2-X 3$ where

(i) X1 stands for the crushable core (PS13, PU30, PU50, ...),

(ii) $X 2$ stands for the crushable core thickness, $l(\mathrm{~mm})$,

(iii) $X 3$ stands for the front plate (FP1, FP2, FP3, ..).

The chronological crushing events of the PU30-050-FP1 and PU30-050-FP3 are presented in Figures 9 and 10. After the detonation of the explosive charge, a blast wave propagates through the explosive driven shock tube. A planar blast wave at the tube end is generated $(t=t 1)$. Hence, an impulsive load is applied on the front plate converting the blast energy to kinetic energy.

$$
E_{k}=\frac{I^{2}}{2 M_{1}}
$$

where $I$ stands for the total impulse (N.s) and $M_{1}$ stands for the front plate mass. Assuming that the total blast energy is converted into kinetic energy, the compression of the crushable core starts with an initial front plate velocity $v_{0}=$ $I / M_{1}$. The foam starts to deform $(t=t 2)$. The densified part moves with the same velocity as the front plate [1]. The undeformed part of the foam core moves with the steel beam under a load governed by the plateau stress $\sigma_{c}$ [3] (Figure 3 ). Depending on the initial velocity $v_{0}$, the crushable core thickness $l$, and the plateau stress $\sigma_{c}$, two cases can take place. The first case consists in the complete densification of the crushable core with a nonzero velocity of the front plate $(t=t 3$; PU30-050-FP1). In this case, the front plate and the fully compacted foam come together with the same velocity to impact the steel beam. The second case consists in 
TABLE 3: Loading parameters and dynamic properties for an elastic-plastic, simply supported beam.

\begin{tabular}{|c|c|c|c|}
\hline Parameter & Symbol/formula & \multicolumn{2}{|c|}{ Values (unit) } \\
\hline Peak reflected pressure & $P_{r}$ & \multicolumn{2}{|c|}{$13.85(\mathrm{MPa})$} \\
\hline Positive phase duration & $t_{d}$ & \multicolumn{2}{|c|}{$0.324(\mathrm{~ms})$} \\
\hline Beam span & $L$ & \multicolumn{2}{|c|}{$0.6(\mathrm{~m})$} \\
\hline Beam mass & $m$ & \multicolumn{2}{|c|}{$1.87(\mathrm{~kg})$} \\
\hline Beam thickness & $d$ & \multicolumn{2}{|c|}{$5(\mathrm{~mm})$} \\
\hline Beam width & $b$ & \multicolumn{2}{|c|}{$80(\mathrm{~mm})$} \\
\hline Moment of inertia & $I_{t}=b d^{3} / 12$ & \multicolumn{2}{|c|}{$833\left(\mathrm{~mm}^{4}\right)$} \\
\hline Young's modulus & $E$ & \multicolumn{2}{|c|}{$240(\mathrm{GPa})$} \\
\hline Yield strength & $\mathfrak{R}_{0.2}$ & \multicolumn{2}{|c|}{$353.85(\mathrm{MPa})$} \\
\hline \multirow[t]{2}{*}{ Load-mass factor } & $K_{\mathrm{LM}}$ & \multicolumn{2}{|c|}{$0.49(-)$} \\
\hline & & Experimental value & Analytical value \\
\hline Beam stiffness & $k=48 E I_{t} / L^{3}$ & 35.5 & $44.4(\mathrm{kN} / \mathrm{m})$ \\
\hline Equivalent mass & $m_{\mathrm{se}}=K_{\mathrm{LM}} m$ & 0.92 & $0.92(\mathrm{~kg})$ \\
\hline Natural period & $T_{0}=2 \pi \sqrt{m_{\mathrm{se}} / k}$ & 32 & $29(\mathrm{~ms})$ \\
\hline Time ratio & $t_{d} / T_{0}$ & $9.510^{-3}$ & $10^{-2}$ \\
\hline Maximum deflection & $y_{\max }$ & 104 & $94(\mathrm{~mm})$ \\
\hline Permanent plastic deflection & $y_{\text {plastic }}$ & 57.57 & $63(\mathrm{~mm})$ \\
\hline Maximum resistance & $R_{\max }$ & 1.4 & $1.3(\mathrm{kN})$ \\
\hline
\end{tabular}

TABLE 4: Experimental results for the investigated sacrificial cladding configurations.

\begin{tabular}{lccccccccc}
\hline & $l(\mathrm{~mm})$ & FP mass $(\mathrm{g})$ & $y_{\max }(\mathrm{mm})$ & $y_{\text {plastic }}(\mathrm{mm})$ & Std $(\%)$ & $T_{0}(\mathrm{~ms})$ & $\epsilon_{\max }(-)$ & $v_{0}(\mathrm{~m} / \mathrm{s})$ & $\mathrm{Eff}(\%)$ \\
\hline Without sc & - & - & 104 & 57.57 & 4.51 & 32 & - & - \\
\hline PS13-050-FP3 & 50 & 336 & 105 & 57.31 & 4.10 & 34 & 0.95 & 34 \\
PS13-050-FP4 & 50 & 495 & 92.53 & 42.34 & 3.60 & 32 & 0.95 & 21 & 13.57 \\
\hline PS13-100-FP3 & 100 & 336 & 84 & 35.16 & 5.80 & 32.5 & 0.90 & 30 & 23.67 \\
PS13-100-FP4 & 100 & 495 & 77 & 24.75 & 1.30 & 32.5 & 0.85 & 22 & 31.95 \\
\hline PU30-050-FP1 & 50 & 144 & 98.03 & 54.47 & 3.70 & 33.8 & 0.95 & 68.5 & 7.06 \\
PU30-050-FP2 & 50 & 188 & 98.13 & 51.59 & 5.70 & 33.7 & 0.90 & 37 & 6.95 \\
PU30-050-FP3 & 50 & 336 & 88.10 & 38.84 & 2.30 & 32.5 & 0.75 & 32 & 18.82 \\
PU30-050-FP4 & 50 & 495 & 67.33 & 23.69 & 4.30 & 33.7 & 0.51 & 23 & 43.40 \\
\hline PU30-100-FP1 & 100 & 144 & 74.96 & 33.10 & 4.65 & 32.6 & 0.72 & 68 & 34.37 \\
PU30-100-FP3 & 100 & 336 & 65.02 & 12.82 & 5.51 & 34.6 & 0.65 & 29.5 & 46.13 \\
PU30-100-FP4 & 100 & 495 & 59.72 & 12.50 & 7.10 & 32 & 0.30 & 21.5 & 52.40 \\
\hline PU30-150-FP1 & 150 & 144 & 70.12 & 22.49 & 2.40 & 32.55 & 0.48 & 69 & 40.09 \\
\hline PU50-050-FP1 & 50 & 144 & 78.25 & 34.06 & 6.10 & 32.5 & 0.92 & 68.5 & 30.47 \\
PU50-050-FP3 & 50 & 336 & 62.27 & 21.94 & 3.40 & 32.5 & 0.70 & 31 & 49.38 \\
\hline
\end{tabular}

the complete deceleration of the front plate (till zero velocity) before reaching the complete densification $(t=t 5$; PU30050-FP3). In this case, the impulsive blast load is converted to a lower pressure (governed by $\sigma_{c}$ ) over a longer time duration.

After the end of the compression process, the front plate goes back together with the foam core (depending on the double-side bonding tape). Due to the transmitted pressure, the midspan point of the steel beam continues to move till a maximum deflection $y_{\max }$ which is followed by a free vibration behaviour around its permanent plastic deformation $y_{\text {plastic }}$. In some cases, the sacrificial cladding remains attached to the steel beam leading to a different free vibration period $T_{0}$ (due to the added mass of the sacrificial cladding to the steel beam).

Several configurations are tested in order to study the effect of both the crushable core properties (plateau stress and thickness) and the front plate mass. The midspan deflection is compared to the configuration without sacrificial cladding. The absorption capacity, reported in Table 4, increases by increasing the front plate mass, the thickness, and the plateau stress of the crushable core. For practical reasons, a light front plate is preferable. Hence, to ensure the expected absorption capacity with a lighter front plate, the plateau stress and thickness should be increased. Due to the low density of 


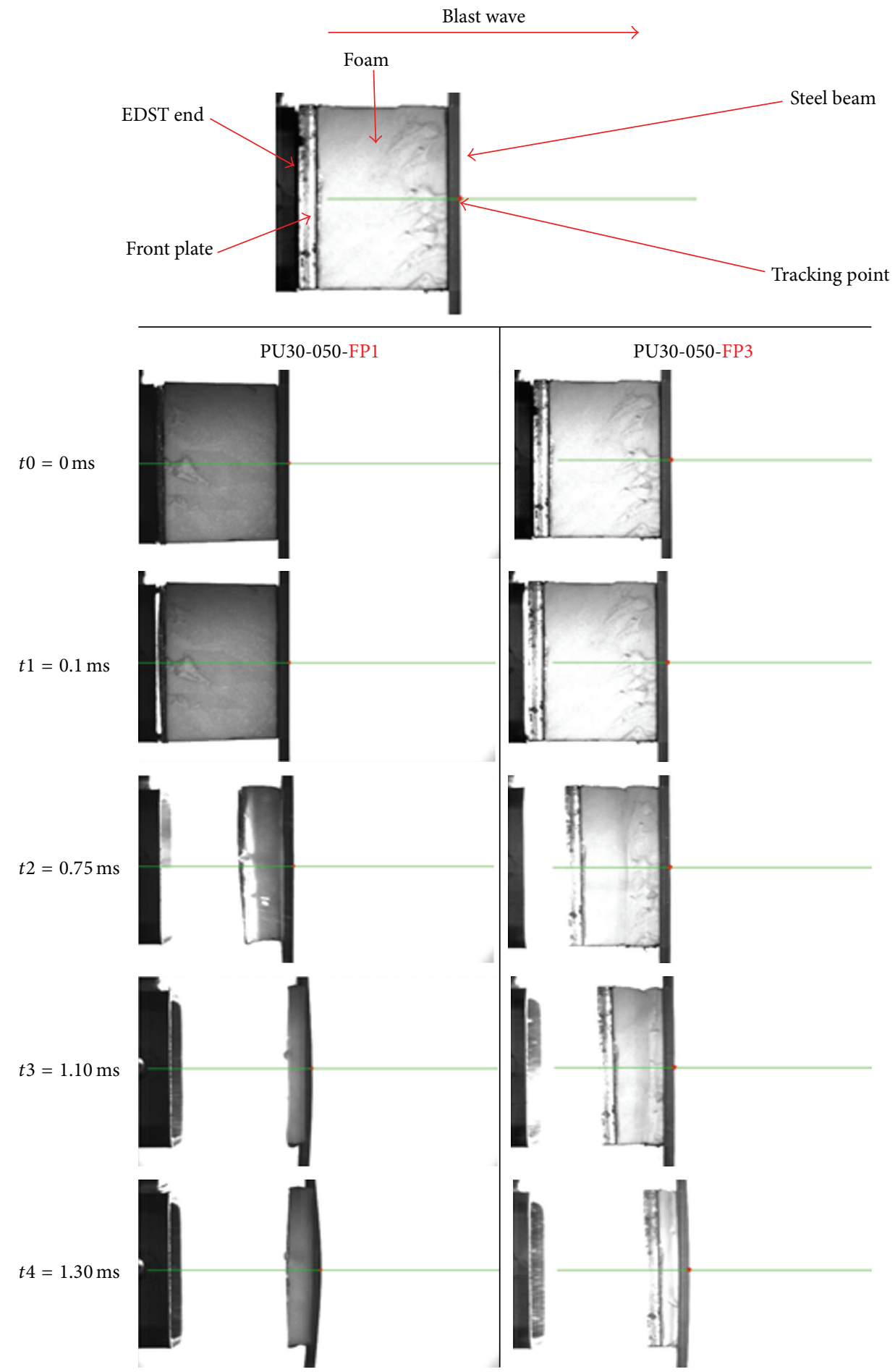

FIGURE 9: The chronological interaction of the simply supported beam with the tested sacrificial cladding configurations: PU30-050-FP1 and PU30-050-FP3.

the tested crushable material, the foam mass is negligible and the thickness can be increased till reaching the desired absorption capacity. However, the increase of the plateau stress is limited by the Ma and Ye criterion (Section 3) and depends on the maximum structure resistance.
4.3.1. Effect of the Crushable Core Thickness. The role of the crushable core is to convert the high reflected pressure generated by the blast wave to a relatively low constant pressure (governed by the plateau stress) over a longer time span. In other words, the role of the crushable material is to stop 




FIGURE 10: The chronological interaction of the simply supported beam with the tested sacrificial cladding configurations: PU30-050-FP1 and PU30-050-FP3.

the accelerated front plate before reaching the densification region (Figure 1). According to Hanssen theory [1], a minimum thickness which depends on the given blast load, the front plate mass, and the plateau stress of the crushable material is needed. Figure 11 illustrates the midspan deflection of the steel beam using sacrificial cladding with the same front plate (FP1) for several PU30 thickness. The dashed lines stand for the permanent plastic deformation of the steel beam.

The results are compared to the beam midspan deflection without sacrificial cladding. Using a thickness of $150 \mathrm{~mm}$, the maximum compression strain is lower than the densification strain $\epsilon_{d}$ (Table 4). The front plate is stopped before the densification region of PU30. The maximum deflection and the permanent plastic deformation are decreased by $32.5 \%$ and $61 \%$, respectively, leading to an absorption capacity of $40 \%$. With a PU30 thickness of $50 \mathrm{~mm}$, the crushable core is fully compacted $\left(\epsilon_{\max }=0.95\right)$. Even a thickness of $100 \mathrm{~mm}$ is still insufficient to stop the front plate before the densification region $\left(\epsilon_{\max }=0.72>\epsilon_{d}\right)$ and an absorption capacity of $34.37 \%$ is recorded.

Similar results are observed with the expanded polystyrene foam PS13 (see Table 4 and Figure 12). The absorption is not ensured by the PS13-050-FP3 configuration. The resulting midspan deflection is similar to the beam response without sacrificial cladding. After the full compaction, an ejection of the material is observed (Figure 13) which is 


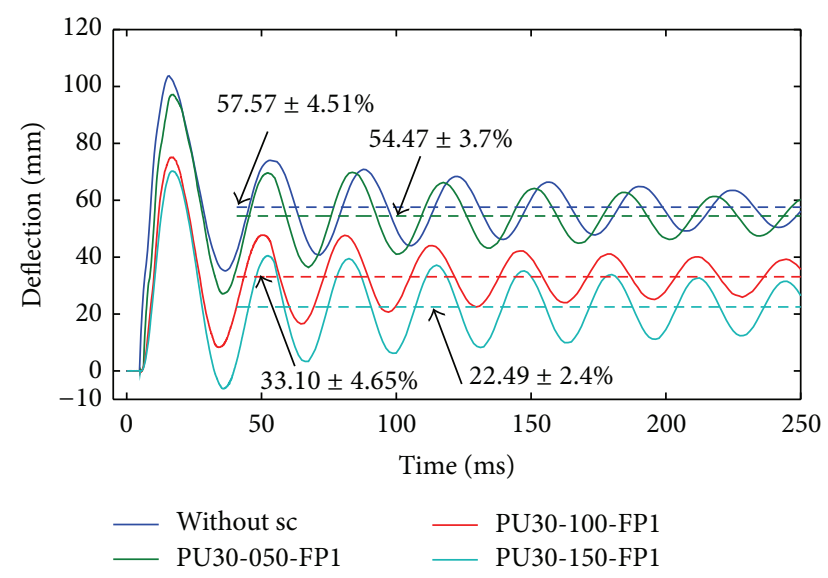

FIGURE 11: The midspan deflection of PU30-050-FP1, PU30-100-FP1, and PU30-150-FP1.

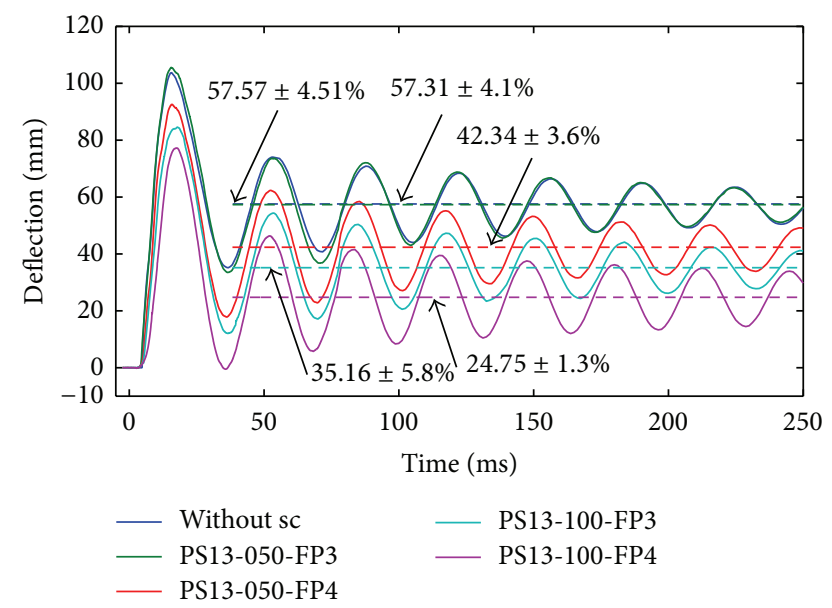

FIGURE 12: The midspan deflection of PS13-050-FP3, PS13-050-FP4, PS13-100-FP3, and PS13-100-FP4.

followed by the impact of the front plate on the structure. An enhancement of the absorption capacity is provided by increasing the thickness and the front plate mass.

4.3.2. Effect of the Crushable Core Plateau Stress. The absorption capacity of the crushable core increases by increasing the plateau stress. Figure 14 displays the midspan deflection for PS13, PU30, and PU50 using the same thickness and the same front plate. Using PU50, the front plate is stopped before reaching the densification strain leading to an absorption capacity of about $50 \%$. For PU30, the densification region is reached without reaching the complete densification. However, as discussed in the previous section, the PS13 is fully compacted and a reduction of the permanent plastic deformation of the steel beam is not ensured.

4.3.3. The Effect of the Front Plate Mass. The role of the front plate is to distribute the loading in a uniform way over the cladding, enabling the crushable core to deform uniformly under compression [6]. The front plate should be rigid enough to guarantee the uniform distribution. If the front plate is not rigid enough, a nonuniform compression of the crushable core can take place which may lead to an incomplete use of the energy absorption capability [6]. In the present work, the front plates are considered rigid. The mass is an important variable as it affects the total kinetic energy that the cladding system needs to absorb (see (4)). Hence, the bigger $M_{1}$ gets, the lower the kinetic energy to absorb will be. Figure 15 illustrates the effect of the front plate mass.

Similar results are observed for PU50 and PS13 and for several crushable core thickness. Figure 16 presents the effect of the front plate on the absorption capacity.

\section{Conclusions and Perspectives}

The purpose of the present paper is to study the effectiveness of sacrificial cladding using polymeric foam as crushable core by means of an adequate experimental setup. The influence of the front plate mass and the crushable core properties (thickness and plateau stress) on the effectiveness is investigated. Three different polymeric foams are tested: (a) the expanded polystyrene foam PS13, (b) the closedcell polyurethane PU30, and (c) the open-cell polyurethane PU50. Four front plate masses are used: 144, 188, 336, and $495 \mathrm{~g}$. All possible combinations are tested to determine their absorption capacity.

To fulfill the aim, an experimental setup is designed comprising an explosive driven shock tube, a high speed camera, and a simply supported steel beam. The use of an explosive driven shock tube helps to generate a controlled planar blast wave focused only on the studied sacrificial cladding system. The high speed camera is used to record the crushing of the cellular material and the beam deflection. The main structure is simulated by a simply supported steel beam under a localized blast load. The beam structure properties (material and dimensions) are selected according to the $\mathrm{Ma}$ and $\mathrm{Ye}$ theory [3].

The steel beam deflection (without sacrificial cladding) under a localized blast load is, first, studied and compared to the single degree of freedom theory. A good concordance is observed. The idealized elastic-plastic model is adopted as a response function of the steel beam and the dissipated energy is calculated. Second, the effectiveness of several sacrificial cladding configurations is studied. The steel beam deflections with sacrificial cladding are measured. Depending on the tested configuration, a reduction of the global response of the main structure is observed. The absorption capacity is calculated by comparing the energy dissipated by the steel beam without protection with the energy dissipated by the steel beam with sacrificial cladding. The absorption capacity increases by increasing the front plate mass, the crushable core thickness, and the plateau stress. But, for practical reasons, it is preferable to use a rigid and lighter front plate. Also, the increase of the plateau stress is limited by the structure resistance. Hence, a minimum thickness of the crushable core may ensure a specific absorption capacity.

Consequently, to achieve a positive protection, the properties of both the foam material and the front plate depend on 


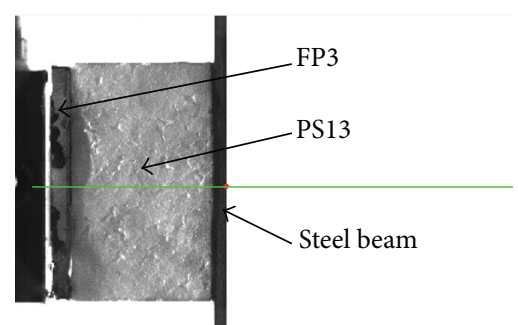

(a)

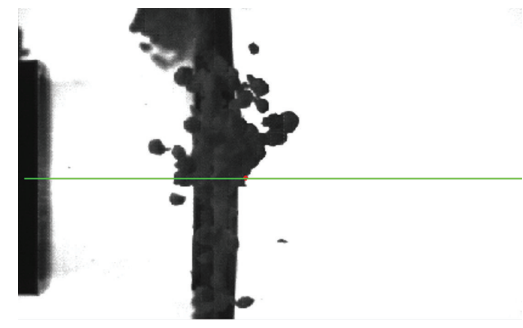

(c)

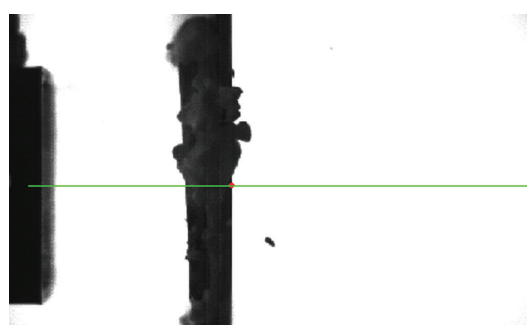

(b)

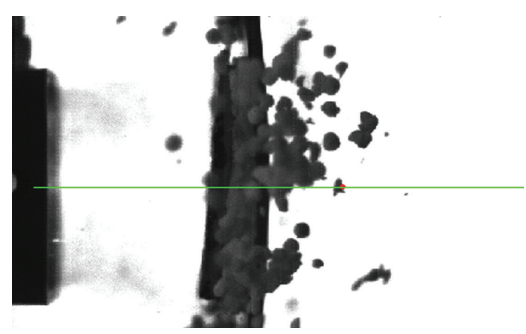

(d)

FIGURE 13: The PS13-050-FP3 configuration before and after the blast load: (a) before the blast load, (b) fully compacted expanded polystyrene, (c) material ejection and front plate impact with the structure, and (d) material ejection and front plate recoil.



FIGURE 14: The experimental results of the midspan deflection of the steel beam with PS13-050-FP3, PU30-050-FP3, and PU50-050-FP3.
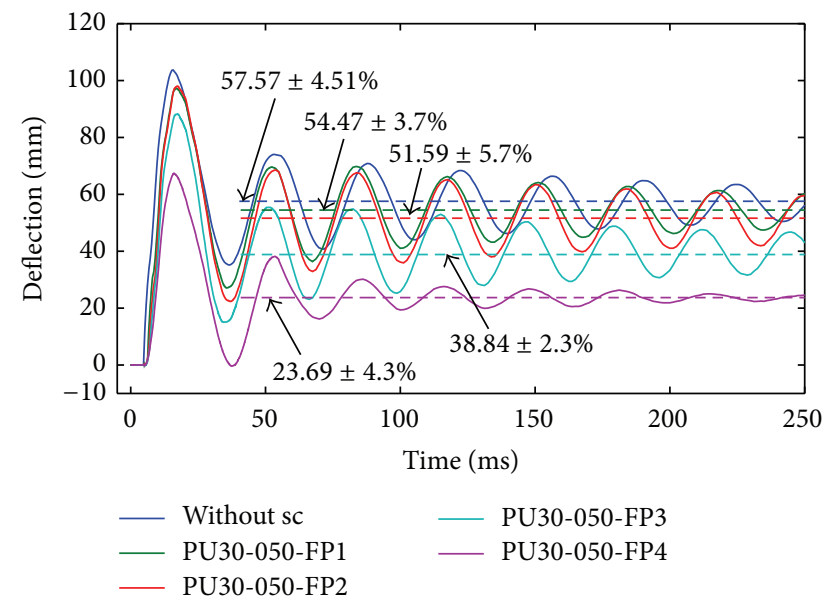

Figure 15: The effect of the front plate mass with a thickness of $50 \mathrm{~mm}$ of polyurethane PU30.

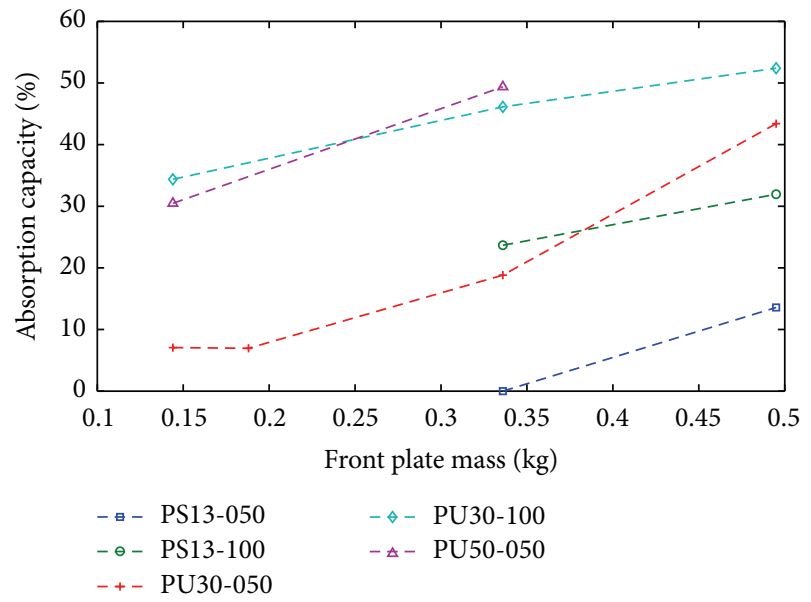

Figure 16: The effect of the front plate mass on the absorption capacity.

the main structure. First, the selected foam material should be characterized by a plateau stress comparable to the resistance of the main structure. Second, for practical reasons, the front plate material should be rigid and light. Third, depending on the selected foam material plateau stress, the pressureimpulse load, and the front plate mass, the minimum foam thickness can be selected using the Hanssen model [1].

In the present work, the open-cell polyurethane PU50 ensures the highest protection level due to its high plateau stress. The expanded polystyrene PS13 presents a lower plateau stress leading to an increased thickness to ensure the same absorption capacity as PU50. However, a disintegration problem is observed which limits its absorption capability. The closed-cell polyurethane PU30 presents considerable effectiveness. 
The effectiveness of the sacrificial cladding is studied using a small specimen scale of $80 \times 80 \mathrm{~m}^{2}$ with only one pressure-impulse combination. An extensive study in large scale and with other pressure-impulse is needed to confirm the obtained conclusions.

\section{Nomenclature}

\begin{tabular}{|c|c|}
\hline$\epsilon_{\max }:$ & Maximum strain in the crushable core \\
\hline$\eta:$ & Energy absorption efficiency \\
\hline$\rho:$ & Steel density \\
\hline A: & Cross-sectional area of the front plate \\
\hline$b:$ & Beam width \\
\hline$d:$ & Beam thickness \\
\hline$E:$ & Young's modulus \\
\hline$E_{0}:$ & $\begin{array}{l}\text { Dissipated energy with the steel beam } \\
\text { without protection }\end{array}$ \\
\hline$E_{k}:$ & Kinetic energy of the front plate \\
\hline$E_{\mathrm{sc}}:$ & $\begin{array}{l}\text { Dissipated energy with the steel beam } \\
\text { with protection }\end{array}$ \\
\hline Eff: & $\begin{array}{l}\text { Absorption capacity of the sacrificial } \\
\text { cladding }\end{array}$ \\
\hline$I:$ & Total impulse (N·s) \\
\hline$I_{t}:$ & Second moment of area \\
\hline$k:$ & Stiffness of main structure \\
\hline$K_{\mathrm{LM}}:$ & Load-mass factor \\
\hline$L:$ & Beam span \\
\hline$l:$ & Crushable core thickness \\
\hline$m:$ & Beam mass \\
\hline$M_{1}:$ & Front plate mass \\
\hline$m_{\mathrm{se}}:$ & Equivalent mass of the main structure \\
\hline$P_{r}:$ & Maximum reflected pressure \\
\hline$R_{m}:$ & Tensile strength \\
\hline$R_{\max }:$ & $\begin{array}{l}\text { Maximum resistance of the main } \\
\text { structure }\end{array}$ \\
\hline $\operatorname{Re}_{0.2 \%}:$ & Yield stress \\
\hline$T_{0}:$ & $\begin{array}{l}\text { Free vibration period of the main } \\
\text { structure }\end{array}$ \\
\hline$t_{d}:$ & $\begin{array}{l}\text { Positive phase duration of the reflected } \\
\text { pressure }\end{array}$ \\
\hline$u:$ & Displacement of the front plate \\
\hline$v_{0}:$ & Initial velocity of the front plate \\
\hline$W:$ & Explosive charge \\
\hline$y:$ & Deflection of the main structure \\
\hline$y_{c}:$ & Critical deflection of the main structure \\
\hline$y_{e}:$ & Elastic deflection of the main structure \\
\hline$y_{\max }:$ & $\begin{array}{l}\text { Maximum deflection of the main } \\
\text { structure }\end{array}$ \\
\hline$y_{\max }(\mathrm{sc}):$ & $\begin{array}{l}\text { Maximum deflection of the steel beam } \\
\text { with sacrificial cladding }\end{array}$ \\
\hline$y_{\text {plastic }}:$ & $\begin{array}{l}\text { Permanent plastic deflection of the } \\
\text { main structure }\end{array}$ \\
\hline EDST: & Explosive driven shock tube \\
\hline FP1: & Front plate with a mass of $144 \mathrm{~g}$ \\
\hline FP2: & Front plate with a mass of $188 \mathrm{~g}$ \\
\hline FP3: & Front plate with a mass of $336 \mathrm{~g}$ \\
\hline FP4: & Front plate with a mass of $495 \mathrm{~g}$ \\
\hline HSC: & High speed camera \\
\hline LCS: & Load-Cladding-Structure \\
\hline
\end{tabular}

$P(t): \quad$ Reflected pressure time history

$P 1: \quad$ Pressure transducer 1 set at the tube end

P2: $\quad$ Pressure transducer 2 set at the tube end

PS13: Expanded polystyrene with a density of $13 \mathrm{~kg} / \mathrm{m}^{3}$

PU30: Closed-cell polyurethane with a density of $30 \mathrm{~kg} / \mathrm{m}^{3}$

PU50: Open-cell polyurethane with a density of $50 \mathrm{~kg} / \mathrm{m}^{3}$

SDOF: Single degree of freedom.

\section{Competing Interests}

The authors declare that they have no competing interests.

\section{Acknowledgments}

The authors are grateful to the Nestaan Holland company for providing the polyurethane specimen PU50.

\section{References}

[1] A. G. Hanssen, L. Enstock, and M. Langseth, "Close-range blast loading of aluminium foam panels," International Journal of Impact Engineering, vol. 27, no. 6, pp. 593-618, 2002.

[2] Q. M. Li and H. Meng, "Attenuation or enhancement-a onedimensional analysis on shock transmission in the solid phase of a cellular material," International Journal of Impact Engineering, vol. 27, no. 10, pp. 1049-1065, 2002.

[3] G. W. Ma and Z. Q. Ye, "Analysis of foam claddings for blast alleviation," International Journal of Impact Engineering, vol. 34, no. 1, pp. 60-70, 2007.

[4] J. J. Harrigan, S. R. Reid, and A. S. Yaghoubi, "The correct analysis of shocks in a cellular material," International Journal of Impact Engineering, vol. 37, no. 8, pp. 918-927, 2010.

[5] M. D. Theobald, G. S. Langdon, G. N. Nurick, S. Pillay, A. Heyns, and R. P. Merrett, "Large inelastic response of unbonded metallic foam and honeycomb core sandwich panels to blast loading," Composite Structures, vol. 92, no. 10, pp. 2465-2475, 2010.

[6] G. S. Langdon, D. Karagiozova, M. D. Theobald, G. N. Nurick, G. Lu, and R. P. Merrett, "Fracture of aluminium foam core sacrificial cladding subjected to air-blast loading," International Journal of Impact Engineering, vol. 37, no. 6, pp. 638-651, 2010.

[7] C. Qi, S. Yang, and R. Gao, "Numerical simulation of force enhancement by cellular material under blast load," Advances in Mechanical Engineering, vol. 2013, Article ID 328651, 10 pages, 2013.

[8] Y. Xia, C. Wu, Z. Liu, and Y. Yuan, "Protective effect of graded density aluminium foam on rc slab under blast loading-an expeimental study," Construction and Building Materials, vol. 111, pp. 209-222, 2016.

[9] C. Wu and Y. Zhou, "Simplified analysis of foam cladding protected reinforced concrete slabs against blast loadings," International Journal of Protective Structures, vol. 2, no. 3, pp. 351-366, 2011.

[10] H. Zhou, Z. Zhao, and G. Ma, "Protection against blast load with cellular materials and structures," International Journal of Aerospace and Lightweight Structures, vol. 2, no. 1, pp. 53-76, 2012. 
[11] X. Li, P. Zhang, Z. Wang, G. Wu, and L. Zhao, "Dynamic behavior of aluminum honeycomb sandwich panels under air blast: experiment and numerical analysis," Composite Structures, vol. 108, no. 1, pp. 1001-1008, 2014.

[12] X. Li, Z. Wang, F. Zhu, G. Wu, and L. Zhao, "Response of aluminium corrugated sandwich panels under air blast loadings: experiment and numerical simulation," International Journal of Impact Engineering, vol. 65, pp. 79-88, 2014.

[13] S. R. Reid and C. Peng, "Dynamic uniaxial crushing of wood," International Journal of Impact Engineering, vol. 19, no. 5-6, pp. 531-570, 1997.

[14] L. Gibson and M. Ashby, Cellular Solids: Structure and Properties, Cambridge Solid State Science Series, Cambridge University Press, 2nd edition, 1999.

[15] W. Chen, H. Hao, D. Hughes, Y. Shi, J. Cui, and Z.-X. Li, "Static and dynamic mechanical properties of expanded polystyrene," Materials and Design, vol. 69, pp. 170-180, 2015.

[16] Q. M. Li, I. Magkiriadis, and J. J. Harrigan, "Compressive strain at the onset of densification of cellular solids," Journal of Cellular Plastics, vol. 42, no. 5, pp. 371-392, 2006.

[17] H. Ousji, B. Belkassem, M. A. Louar et al., "Parametric study of an explosive-driven shock tube as blast loading tool," Experimental Techniques, vol. 40, no. 4, pp. 1307-1325, 2016.

[18] H. Ousji, B. Belkassem, M. Louar, B. Reymen, L. Pyl, and J. Vantomme, "Numerical and experimental study of polyurethane foam used as core material in sacrificial cladding for blast mitigation," in Proceedings of the 16th International Symposium for Interaction of the effects of Munition with Structures (ISIEMS '15), 2015.

[19] P. Smith and J. Hetherington, Blast and Ballistic Loading of Structures, Butterworth-Heinemann, Boston, Mass, USA, 1994. 


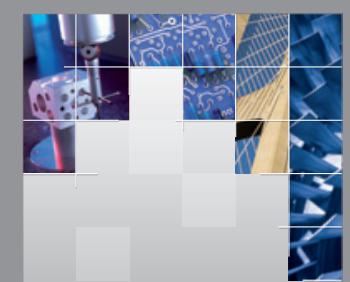

\section{Enfincering}
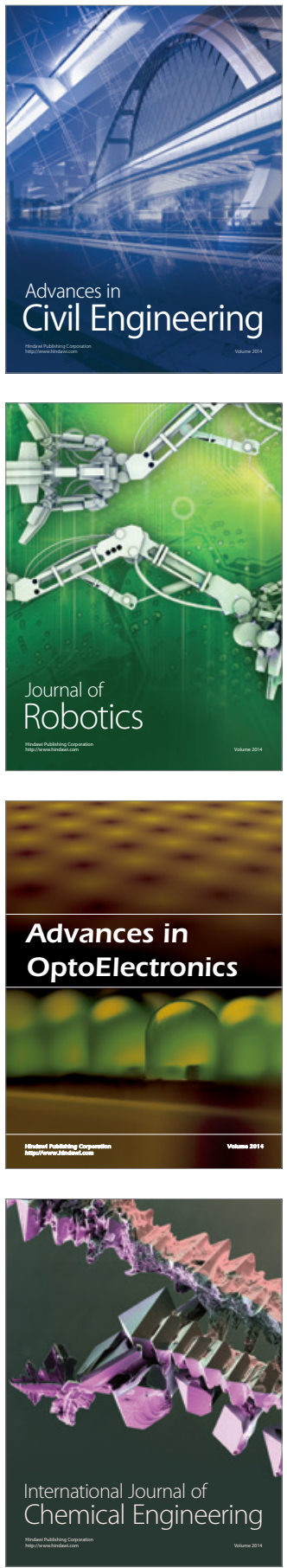

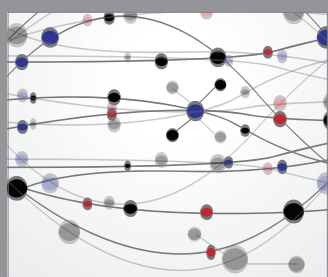

The Scientific World Journal

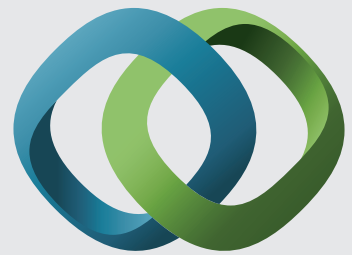

\section{Hindawi}

Submit your manuscripts at

http://www.hindawi.com

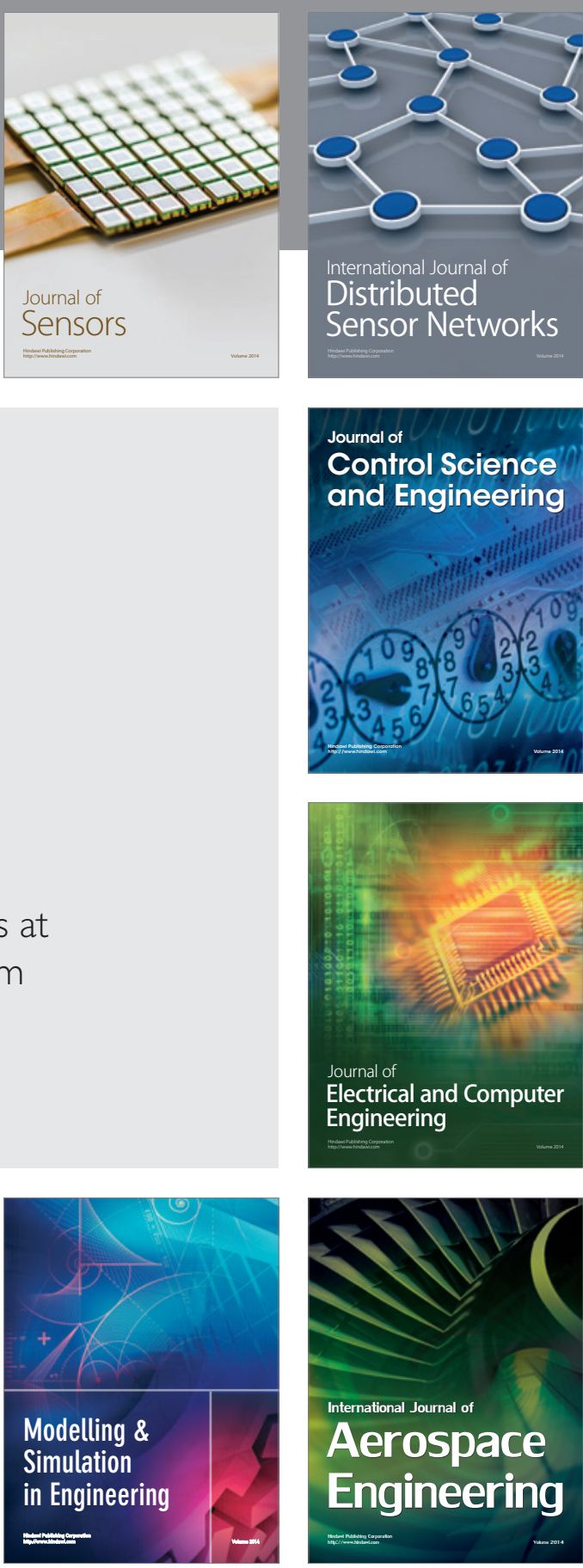

International Journal of

Distributed

Sensor Networks

Journal of

Control Science

and Engineering
